\title{
Green Body Behaviour of High Velocity Pressed Metal Powder
}

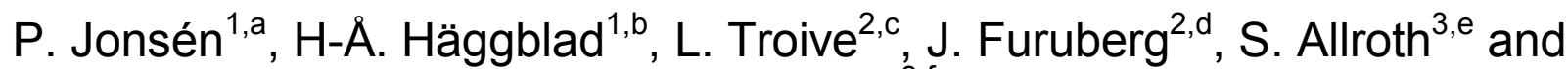 P. Skoglund ${ }^{3, f}$}

${ }^{1}$ Division of Solid Mechanics, Luleå University of Technology, Sweden

${ }^{2}$ Hydropulsor $A B$, Sweden

${ }^{3}$ Höganäs $A B$, Sweden

\author{
apar.jonsen@ltu.se, bhans-ake.haggblad@ltu.se, 'lars.troive@hydropulsor.com, \\ djoachim.furuberg@hydropulsor.com, e'sven.allroth@hoganas.com, fpaul.skoglund@hoganas.com
}

Keywords: High velocity compaction, green strength, springback, metal powder, compressibility.

\begin{abstract}
High velocity compaction (HVC) is a production technique with capacity to significantly improve the mechanical properties of powder metallurgy (PM) parts. Several investigations indicate that high-density components can by obtained using HVC. Other characteristics are low ejection force and uniform density. Investigated here are green body data such as density, tensile strength, radial springback, ejection force and surface flatness. Comparisons are performed with conventional compaction using the same pressing conditions. Cylindrical samples of a pre-alloyed water atomized iron powder are used in this experimental investigation. The different behaviour of HVC-pressed green bodies compared to conventional pressed green bodies are analysed and discussed. The HVC process in this study resulted in a better compressibility curve and lower ejection force compared to conventional quasi static pressing. Vertical scanning interferometry (VSI) measurements show that the HVC process gives flatter sample surfaces.
\end{abstract}

\section{Introduction}

A number of investigations of the High Velocity Compaction (HVC) process have been published in recent years [1-5]. All publications indicate that high-density components can be obtained using HVC. Other characteristics are low springback, low ejection force and uniform density. This paper describes an experimental investigation aimed at comparing the $\mathrm{HVC}$ and Conventional Compaction (CC) processes in general. Great care has been taken to compare the two processes under identical conditions, i.e. tooling set up, powder material, lubricant, etc. High-density PM samples have been compacted using both HVC and CC. Geometrical properties and green strength of the samples have been studied.

\section{Experimental Procedure}

In order to compare HVC with conventional quasi static compaction, the experiments have been performed under the same conditions. During the different experiments the tool set, powder material, force sensor, data acquisition equipment and sample geometry were identical.

Die and punch Assembly. The tool set used during the experiments consists of a top punch, bottom punch and a die. The upper and bottom punch are manufactured of high speed sinter steel. The die contains a shrink fit pre-tensioned hard metal insert. The diameter of both punches was 25 $\mathrm{mm}$ and the radial clearance between punches and die was $0.010-0.015 \mathrm{~mm}$. The height of the top and bottom punch $80 \mathrm{~mm}$ and $30 \mathrm{~mm}$, respectively, the height of the die $90 \mathrm{~mm}$.

Metal Powder Material. The powder material used for the investigation was a press-ready mix containing Astaloy Mo $+0.3 \%$ graphite (uf-4) $+0.6 \%$ Kenolube. Astaloy Mo is a pre-alloyed water atomized iron powder with 1.5\% Molybdenum, from Höganäs AB Sweden. Kenolube is a lubricant from the same supplier. The theoretical pore free density of this mix is $7.45 \mathrm{~g} / \mathrm{cm}^{3}$. Green strength measurements was also performed for a press-ready mix containing Distaloy $\mathrm{AE}+0.5 \%$ graphite (uf-4) $+0.6 \%$ Kenolube with the theoretical pore free density of $7.48 \mathrm{~g} / \mathrm{cm}^{3}$.

High Velocity Compaction. The High Velocity Compaction experiments were performed using a laboratory HVC-machine with a hydraulic driven hammer. This machine has a maximum capacity of 
$4 \mathrm{~kJ}$. The hydraulic hammer consists of two parts: The hydraulic piston and a weight, which is connected to the piston rod. The hydraulic oil pressure applied on the hydraulic piston is constant and thereby also the force accelerating the piston and the weight. The total mass accelerated was $31 \mathrm{~kg}$. Due to the constant acting force, the energy level is easily adjustable by varying the acceleration distance of the hammer, i.e. the distance between the start position and the impact position. The level of energy can be calculated by multiplying the accelerating force and the distance. Further, the machine was equipped with a load-cell, located under the bottom punch. Load cell data were acquired by a high speed measuring system, capable to measure very sharp and short peak loads due to the impact, see e.g. [3]. The sampling rate in this case was $200 \mathrm{kHz}$. The HVC process starts typically with a pre-compaction, during which the powder is compacted from the apparent density to a density of $4-5 \mathrm{~g} / \mathrm{cm}^{3}$ and thereby the main amount of air is evacuated from the cavities. During the HVC experiments the die was mechanically fixed, i.e. the die was not floating.

Conventional Compaction. The Conventional Compaction experiments were performed using a manual 40 ton workshop press and a semi-automatic 100 ton workshop press. The 40 ton press was used for the compaction pressures up to $800 \mathrm{MPa}$ and the 100 ton press was used for compaction pressure larger than $800 \mathrm{MPa}$. During CC the compaction force was measured with the load cell also used for the HVC experiments. The load-cell was placed under the bottom punch. By using an amplifier equipped with a peak detector memory function, the maximum force applied could easily be measured.

Ejection of the Green Samples. The ejection experiments were performed by using the force of the vertical moveable table of a milling machine. This method may not be very conventional, but worked very well. The die was placed on the moving table. The head of the milling machine functioned as a mechanical stop providing the counterforce that was applied on the top punch when the die table was moved upwards. The counter force was measured continuously using a load-cell placed between the punch and the milling-head. The ejection speed was set to $4.75 \mathrm{~mm} / \mathrm{second}$ and samplings rate during the measurement of the ejecting force was set as high as $10 \mathrm{kHz}$ to allow measurements of possible initial static friction peak loads.

Diametral Compression Tests. The green tensile strength is studied by performing diametral compression of discs. The final sample height is approximately $5 \mathrm{~mm}$ and the diameter is $25 \mathrm{~mm}$. The experimental setup for diametral testing consists of a frame in which two fixtures and a load cell are integrated. The load cell measures forces up to $5 \mathrm{kN}$ with an accuracy of $\pm 0.5 \mathrm{~N}$. To be able to measure the load on the tested disc without influence of friction between pistons and frame, the load cell was mounted between the two plates of the frame. The load under the compressive loaded surface must be distributed so that the compressive and shear stresses in the loading area are reduced enough to ensure tensile failure at the centre of the disc. To this end, the load is distributed over a small arc of a finite width; this is done with an arc radius of $12.7 \mathrm{~mm}$ in the fixture.

Vertical Scanning Interferometry. Profile measurements of HVC and CC pressed $25 \mathrm{~mm}$ circular discs have been performed with a Wyko NT1100 using vertical scanning interferometry (VSI). The technique uses the bright and dark pattern which is a result of the splitting of a beam where one part is reflected against an internal reference surface and the other of the sample. After reflection the beams recombine in the interferometer and the patterns of constructive and destructive interference occur. Each scanning covers an area of $3.8 \times 5.0 \mathrm{~mm}^{2}$. To measure a disc multiple scanning are performed and the results are stitch together. An overlap of $20 \%$ is used in each scan and the pixel size is $13.14 \mu \mathrm{m}$ in the horizontal-plane. The vertical resolution is $3 \mathrm{~nm}$ with maximum error less than $0.5 \%$.

\section{Results}

The impact compaction force curve was measured during each HVC experiment. A single HVC compaction results in several force peaks, see e.g. [3]. This is because the hydraulic hammer bounces on the top punch until the impact energy dissipates. The compaction pressure is calculated according to the first and highest force peak.

Overall Density. In Fig. 1a the density as a function of applied pressure is shown. The HVC density curve is on the average 0.5 percent higher than the $\mathrm{CC}$ density curve. The figure shows that to achieve $98.5 \%$ of the theoretical density the compaction pressure for HVC is approximately 900 
$\mathrm{MPa}$. To achieve the same density with $\mathrm{CC}$ a compaction pressure of approximately $1200 \mathrm{MPa}$ is required i.e. a compaction pressure difference of $300 \mathrm{MPa}$.

Ejection Forces. Fig. 1b show the ejection curves that were measured of some HVC compacted samples and conventional compacted samples. The main difference between the two figures is the value of the static friction force during the first phase of the ejection. This value is approximately twice as high for CC compared to HVC. A smaller difference can be seen for the dynamic friction force during the second phase of the ejection, but also here the ejection force of the HVC samples is lower.
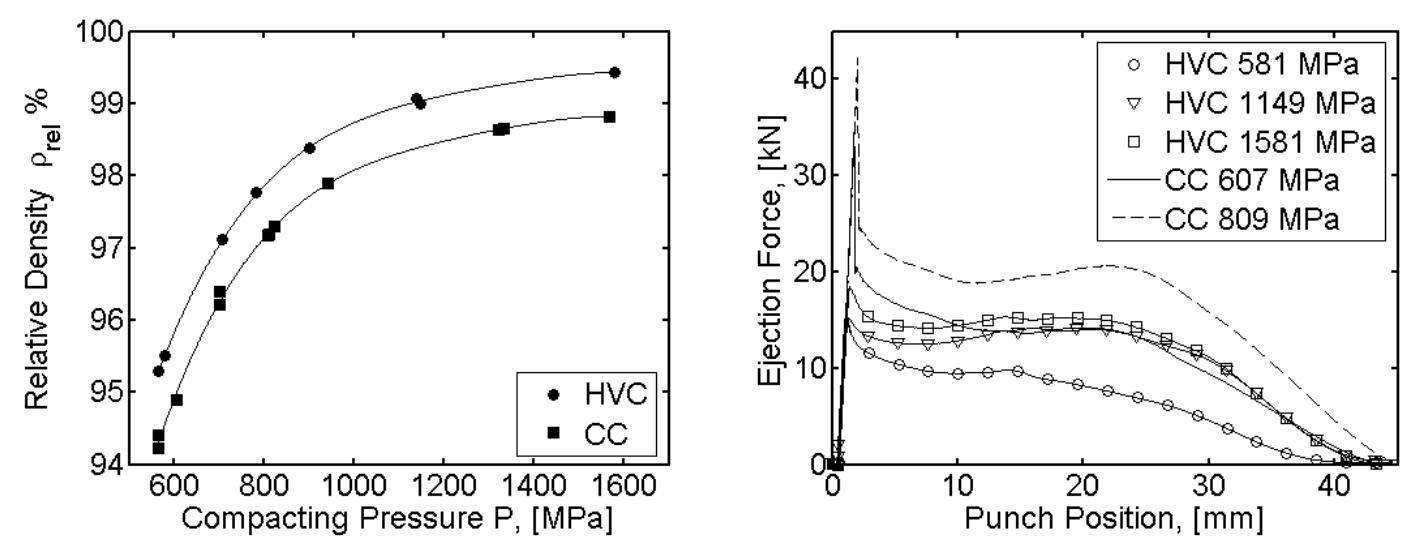

Figure 1. a) Density vs compaction pressure for both CC and HVC. b) Ejection curves for samples compacted by HVC and $\mathrm{CC}$ with different compaction pressures.

Radial Springback. The springback was calculated by dividing the diameter of the die by the diameter of the sample, see Fig. 2a. The HVC samples have a lower springback compared to the CC samples which also partly can be concluded from Fig. $1 \mathrm{~b}$.

Green Strength. The tensile strength, $\sigma_{\mathrm{f}}$, is the maximum tensile stress value for the material. The tensile strength defined as the stress value when a large vertical crack in the centre of the disc is initiated, see [6]. The tensile strength is except for Astaloy Mo also tested for Distaloy AE. Fig. 2b and Fig. 2c shows that $\mathrm{CC}$ discs have slightly higher tensile strength then HVC discs for equal density.
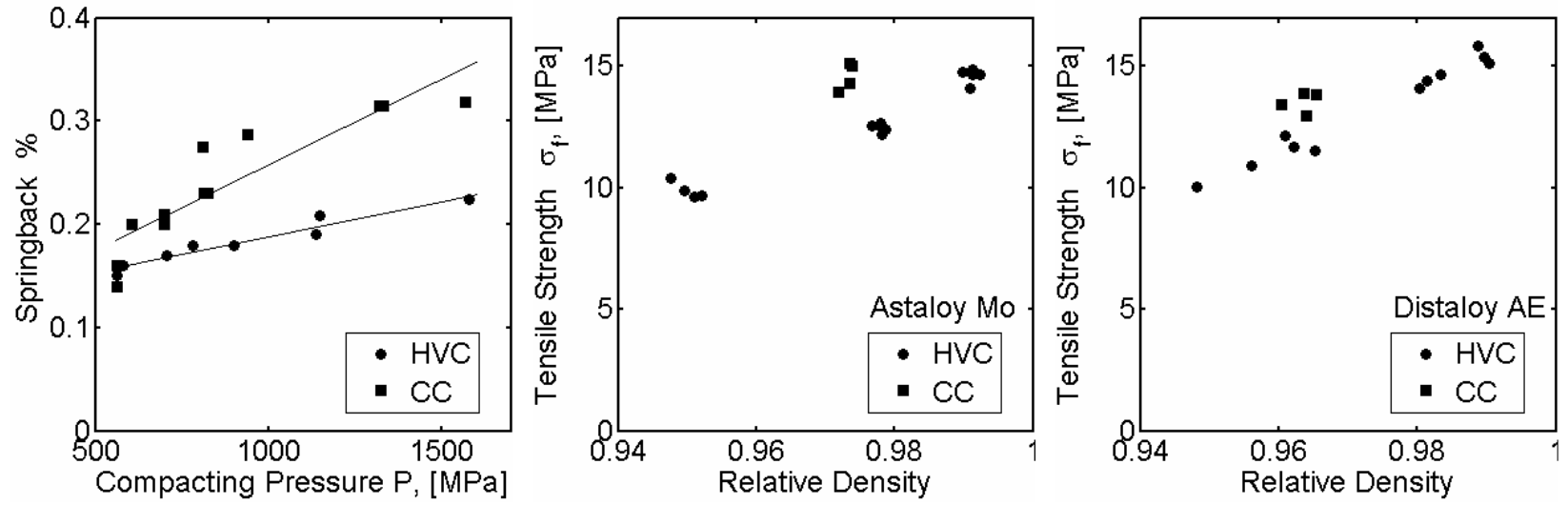

Figure 2. a) Comparison of radial springback between CC and HVC. b) Comparison of tensile strength vs density for Astaloy Mo. C) Comparison of tensile strength vs density for Distaloy AE.

Profile Shape. The surface profile of $25 \mathrm{~mm}$ diameter and $5 \mathrm{~mm}$ high HVC and CC discs with similar densities are compared. The pressing has a single sided action applied with the top punch during compaction followed by a downward ejection. Both upper- and lower side of HVC- and CC discs have a dished profile. For comparable densities the HVC discs have a flatter upper surface, about $6 \mu \mathrm{m}$ difference in height from the centre to the edge of the disc compared to $18 \mu \mathrm{m}$ for CC discs, see Fig. 3a and Fig. 3b. On the lower surface, CC discs seams to have a deeper dish $35 \mu \mathrm{m}$ compared to $25 \mu \mathrm{m}$ for $\mathrm{HVC}$, but no large differences between $\mathrm{HVC}$ and $\mathrm{CC}$ pressed discs are found regarding the lower side. For HVC discs manufactured with high energy impact and densities close to the theoretical pore free density the upper- and lower surface of HVC discs appear to have a dome 
in the centre, see Fig. 3c.
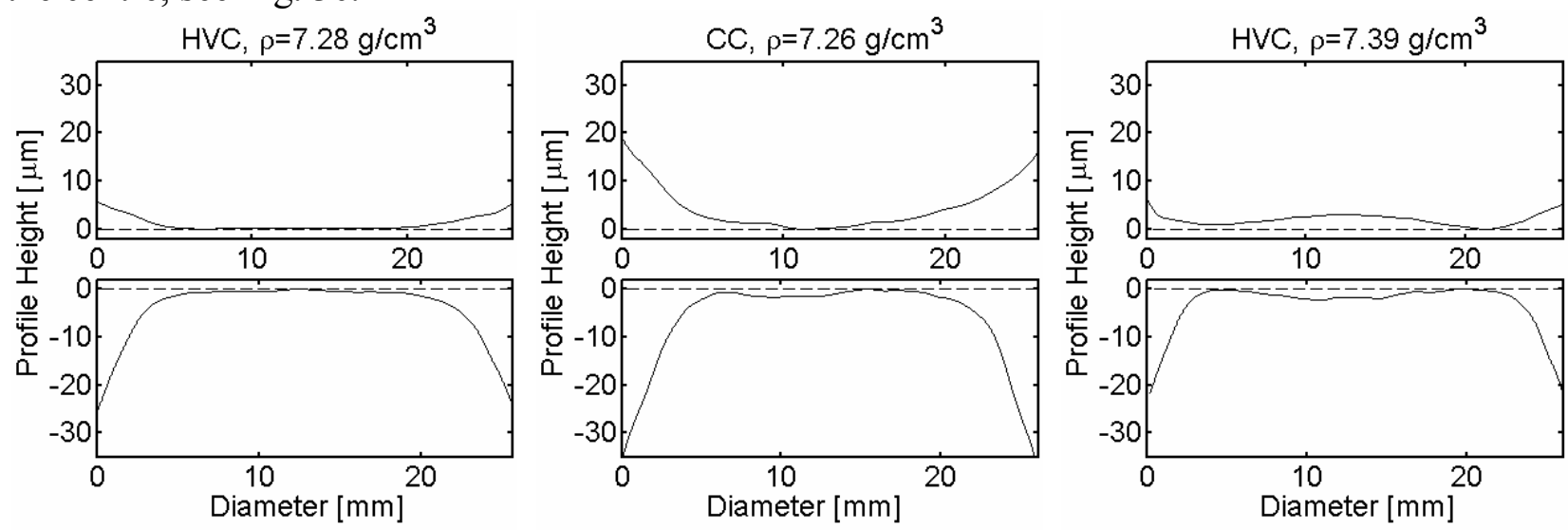

Figure 3. a) Typical profile shape of a HVC disc, upper and lower $2 d$ profile. b) Profile shape of a typical CC disc. c) Profile shape for a high density HVC disc.

\section{Discussion and Conclusions}

To compare HVC and CC processes identical conditions were applied. The main difference between the processes in this study is the velocity of the top punch and the several very sharp and short peak loads during a single high velocity impact. The first conclusion is that the HVC process in this study resulted in a higher compressibility compared to conventional quasi static compaction. The second conclusion is that the HVC samples need lower ejection forces and have lower radial springback compared to $\mathrm{CC}$ samples. Tensile strength in green condition is slightly lower for HVC samples. Both HVC and CC samples have dished shaped end surfaces, but the surface profile of a HVC sample is flatter then for a CC sample. Both statements in the second conclusion indicate that HVC probably allows a lower lubricant consumption and still have better ejection performance compared to CC. A part of the next step of this investigation will be to decrease the lubricant supply until comparable ejection conditions are reached and then investigate compressibility, green strength and springback.

\section{References}

[1] P. Skoglund, High Density PM Parts by High Velocity Compaction, Powder Metallurgy, Vol. 44, No 3, (2001), p. 199.

[2] P. Doremus, F Duwa, P. Francois, G. Puente, C.H. Allibert, High Velocity Compaction, Proceedings PM2TECH 2002, Vol. 4, MPIF, Orlando, USA, (2002), p. 96.

[3] A. Skagerstrand, High Velocity Compaction of Metal Powders, a Study on Density and Properties, Proceedings PM2TECH 2002, Vol. 4, MPIF, Orlando, USA, (2002), p. 111.

[4] D. R. Kumar, R. K. Kumar, P. K. Philip, Investigation on Dynamic Compaction of Metal Powders, Powder Metallurgy, Vol. 45, No 3, (2002), p. 219.

[5] G. Hinzmann, D. Sterkenburg, High-Density Multi-Level PM Components by High Velocity Compaction, Proceedings PM2004 Vienna, Austria (2004)

[6] P. Jonsén, H.-Å. Häggblad, Tensile fracturing in diametral compression, Proceedings PM2005, Vol. 3, EPMA, Prague, Czech Republic (2005), p. 377. 
Progress in Powder Metallurgy

doi:10.4028/www.scientific.net/MSF.534-536

Green Body Behaviour of High Velocity Pressed Metal Powder doi:10.4028/www.scientific.net/MSF.534-536.289 